\title{
Technique for ensuring safety of transportation vehicles through the analysis of their structural reliability
}

\author{
Sergei Repin ${ }^{1 *}$, and Stanislav Evtyukov ${ }^{1}$ \\ ${ }^{1}$ Saint Petersburg State University of Architecture and Civil Engineering, 190005 Saint Petersburg, \\ Russia
}

\begin{abstract}
The article is devoted to the development of a technique for the assessment of the influence of the structural reliability of transportation vehicles on their safety. This technique includes: an analysis of the automotive vehicle as a complex technical system, its structural elements greatly influencing road safety (RS); calculation of mean-time-betweenfailures and time for recovery of subsystems, assemblies and parts, probability of failure-free operation. As a result of the technique application, recommendations as to intervals of the replacement of automotive vehicle's elements depending on the required probability of failure-free operation are released.
\end{abstract}

\section{Introduction}

The necessity for elaboration of the technique for the assessment of the influence of the structural reliability of transportation vehicles on the road safety is caused by the need to take urgent measures for the reduction of the number of road accidents due to transportation vehicles which has steadily increased for the last four years [1]. Reduction of the number of road accidents for this reason is possible only by enhancing the operational reliability of transportation vehicles.

Methods for control of the reliability of complex technical systems with technical operation means developed in aviation [3], automotive transport [4, 5], and other fields [6,7] are known. A particularly clear approach is shown in works of Lukinskiy V. S. and Zaitsev E. I. [5], based on the detection of parts limiting the reliability (PLR), which are subject to priority repair or replacement. Systems of the automotive vehicle, failure of which is the most common cause of road accidents, are determined [9, 10, 12]. However, the engineering technique, which can be used by a transportation mechanic, has not been developed yet.

The goal of this article is to develop such technique. The research object is a transportation vehicle. The research subject is methods of the reliability control with regard to technical operation means. The article methodology includes the theory of reliability, technical operation, collection and processing of the operational information.

*Corresponding author: repinserge@mail.ru 
In the course of working on the article, works of authors in the field of road safety, theory of reliability, technical operation of transportation vehicles, and mathematical programming were used $[7,8,11]$.

Russia ranks first among countries of Europe and North America as to fatal road accidents per 100,000 residents and sixth in terms of 100,000 automotive vehicles giving way only to Ukraine, Albania, Moldavia, Romania and Belarus [1, 12].

From the crisis year 2008 till the year 2015, the Russian light automotive vehicle fleet increased 2-fold [2]. The growth of throughput capacity of enterprises providing maintenance and repair of automotive vehicles amounted to only $30 \%$ for this period. As a consequence, the number of road accidents increased in the country as a whole.

\section{Material and methods}

The methodology of the article includes the theory of reliability, technical operation, collection and processing of operational information.

Statistical data were processed using Microsoft Excel and Mathcad.

In writing the article used the work of the authors in the field of OBD, reliability theory, technical operation of the vehicle, mathematical programming [7, 8, 11, 13-15, 17-23].

\section{Theory}

The Russian State Motor Vehicle Inspectorate calculated the complete statistics as to road accidents in the Russian Federation for the year 2015. It showed that the total number of road accidents almost had not changed (204,068 road accidents).

However, there is a significant leap as to the number of road accidents in the Russian Federation due to operation of malfunctioning transportation vehicles (OMTV) in 2013 (by $50 \%$ as compared to 2012 ), by $24 \%$ more in 2014 and by $15 \%$ more in 2015 . It is evident that the increase in the number of road accidents due to OMTV is caused by the decrease of the operational reliability of transportation vehicles. A deeper analysis of road accident reasons allows arguing that the actual number of road accidents caused by malfunctioning is higher. This opinion is confirmed in interviews with 11,500 drivers involved in road accidents, $32 \%$ of which specified such reason of road accidents as malfunctioning of the brake system, in particular ABS, or its failure [9].

The study of the distribution of road accidents caused by sudden failures of automotive vehicle's systems showed that the brake system had the highest impact - 32-50\% $[9,10$, $12,13,16]$, external lights and alarm system $-16-23 \%$, tires $-12-15 \%$, steering $-11-$ $14 \%$.

It is evident that the decrease in the number of road accidents due to malfunctioning is possible only due to enhancing of the reliability of transportation vehicles. The probability of automotive vehicle being in operable condition is determined by the interaction of failure and recovery flows. For example, the probability of failure-free operation during the time interval $\Delta T$ is as follows [4]:

$$
P(t)=\exp [-\Lambda(t) \cdot \Delta T]
$$

where, $\Lambda(t)$ is reduced failure rate; $t$ is operation life of a transportation vehicle (instead of operation life it is possible to use mileage).

$$
\Lambda(t)=1 /\left[T_{\mathrm{f}}(t)+T_{\mathrm{r}}\right] h^{-1}
$$

where, $T_{\mathrm{f}}(t)$ is time between failures; $T_{\mathrm{r}}$ is recovery time after failure. 
Values, which are reciprocal of $T_{\mathrm{f}}(t)$ and $T_{\mathrm{r}}$, represent the rate of failures $\lambda(\mathrm{t})$ (maintenance requests) and recoveries $\mu(\mathrm{t})$ :

$$
\lambda(\mathrm{t})=1 / \mathrm{T}_{\mathrm{f}}(\mathrm{t}), \mu(\mathrm{t})=1 / \mathrm{T}_{\mathrm{r}} .
$$

Constructive relations between elements of any complex technical object can be presented in the form of a tree structure consisting of systems (engine, frame, transmission, etc.), which are assembled from units comprising complex parts (wheel assembly), consisting, in their turn, of simpler parts:

- Systems of a vehicle - $I$.

- Each $I$-th system contains the number of units $J_{I}$.

- Each $J_{I}$-th unit contains the number of complex parts $K_{I J}$.

- Complex parts consist of simpler ones in the quantity $L_{I J K}$.

- Gradation continues till the last non-assembled part.

- Since practically all elements of an automotive vehicle are connected in series, the probability of failure-free operation $P_{0}$ of a vehicle itself, its systems $P_{I}$, units $P_{I J}$ and parts $P_{I J K}$ can be described with the use of single-type equations:

$$
P_{0}=\prod_{i=1}^{I} P_{i}, P_{I}=\prod_{j_{I}=1}^{J_{I}} P_{j_{I}}, P_{I J}=\prod_{k_{J I}=1}^{K_{J I}} P_{k_{J I}}, P_{I J K}=\prod_{l_{K J I}=1}^{L_{K J I}} P_{l_{K J I}}
$$

Beginning of vehicle operation is the common reference point for the resource of all elements of a complex system. Due to the fact that system elements have different values of life characteristics, failures of elements will take place in random time intervals which become the initial reference point for the resource of elements. At the beginning of operation, a vehicle consists of only new (factory) elements, failure probability of which is significantly lower than in units replaced during repair. With the aging of a vehicle, the replacement of various elements takes place.

The total rate of the steady flow of failures of the system $\lambda_{0}$ will be composed of rates of failure flows with regard to elements $\lambda_{\mathrm{i}}$.

Since elements in the system are, as a rule, engaged in series, then failure of an element leads to failure of the entire system. Thus, by analogy with equation (4), the rate of failures of a vehicle, its systems, units and parts can be described as follows:

$$
\lambda_{0}=\sum_{i=1}^{I} \lambda_{i}, \quad \lambda_{I}=\sum_{j_{I}=1}^{J_{I}} \lambda_{j_{I}}, \quad \lambda_{I J}=\sum_{k_{J I}=1}^{K_{J I}} \lambda_{k_{J I}}, \quad \lambda_{I J K}=\sum_{l_{K J I}=1}^{L_{K J I}} \lambda_{l_{K J I}}
$$

Failures of elements of a complex recoverable system can be considered as not related. Therefore, time between failures will be a random value, resulted from the process without an after effect and distributed exponentially [7].

The rate of failures of automotive vehicle's elements depends on time of its operation (mileage). We use only the queueing theory for the description of the probability of vehicle states on the basis of the information about the rate of failures $\lambda_{i}(t)$ and recoveries $\mu_{i}(t)$ which are independent from the $n$-th number of units.

A vehicle consists of a large number of elements, malfunction of which is eliminated by repair in the course of operation. Alternately, at random time intervals, a vehicle can change its operable condition $\left(S_{0}\right)$ to the condition of failure of the first element $\left(S_{l}\right)$ or second element, etc. till $S_{n}$. Downtime due to repair, especially due unscheduled repair, is also a random value depending on the nature of element damage, availability of spare parts, etc. If 
we take failures and recoveries to be the simplest, then a vehicle can be considered as a queueing system (QS) shown in Figure 1.

For the steady condition, the QS graph can be described by Kolmogorov equations [4, 7]:

$$
\left\{\begin{array}{l}
-P_{0} \lambda_{1}+F_{1} \mu_{1}=0 \\
-P_{0} \lambda_{2}+F_{2} \mu_{2}=0 \\
\cdots \ldots \\
-P_{0} \lambda_{n}+F_{n} \mu_{n}=0 \\
P_{0}+F_{1}+F_{2}+\ldots+F_{n}=0 .
\end{array}\right.
$$

where, $P_{0}, F_{1}, F_{\mathrm{n}}$ are probabilities of system being in operable condition (no failures), with failure of the first element, with failure of the $n$-th element, respectively; $\lambda_{1 \ldots \mathrm{n}}$ and $\mu_{1 \ldots \mathrm{n}}$ are the corresponding rates of failures and recoveries.

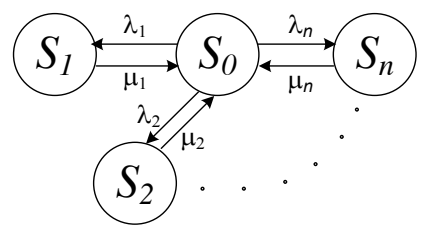

Fig. 1. Graph of states of a vehicle as a complex recoverable system.

Solving the system of the equations, it is possible to express probabilities of all states:

$$
F_{i}(t)=P_{0}(t) \frac{\lambda_{i}(t)}{\mu_{i}(t)} ; P(t)=\left[1+\sum_{i=1}^{n} \frac{\lambda_{i}(t)}{\mu_{i}(t)}\right]^{-1}
$$

where, $F_{i}$ is the probability of vehicle being in the state of failure of the $i$-th element. If we consider only sudden failures leading to changes from the operable condition to the nonoperable one, the second equation will correspond to the factor of availability.

Figure 2 shows results of calculating probabilities of states of transportations vehicles' systems (using the example of VAZ light automotive vehicles) according to equations (1)(6), carried out on the basis of our studies.

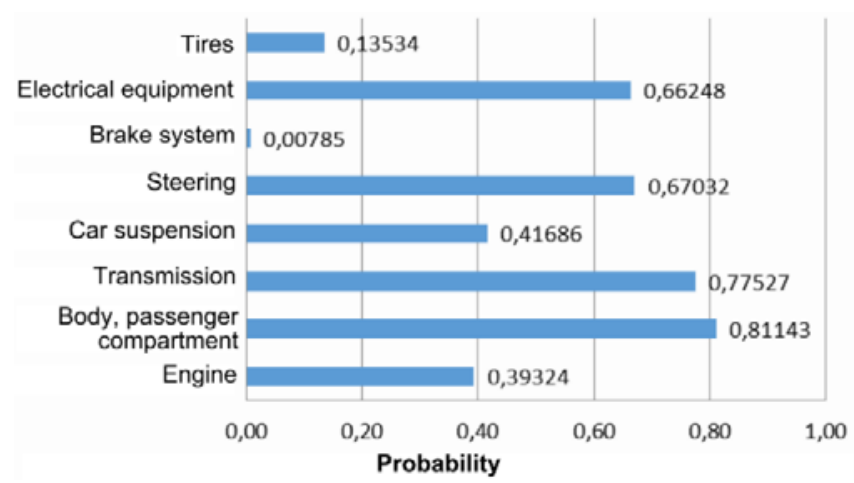

Fig. 2. Probability of failure-free operation of transportation vehicles in the course of one year.

An analysis of structural reliability of the brake system of a transportation vehicle, as exerting the greatest influence on road safety, is give below. The described technique allows assessing the actual reliability of a transportation vehicle and contribution of its individual elements in it. In order to control the reliability by methods of technical service, it is required 
to determine replacement intervals for elements by the required reliability level according to recommendations [7]. Let us consider this technique using the example of a break hose (BH), which, following our studies, causes sudden failures of the brake system most frequently. On the basis of the data on maintenance of VAZ automotive vehicles [7, 13], the information about brake hose time-between-failures is obtained (see Figure 3). T

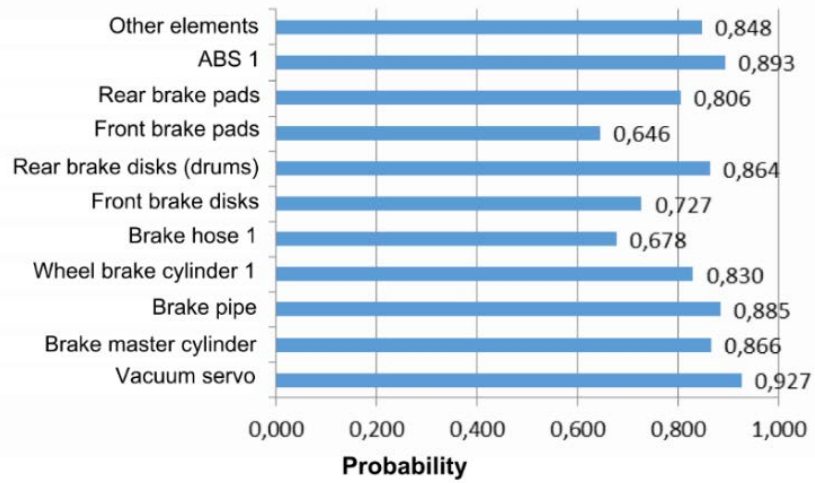

Fig. 3. Probability of failure-free operation of elements of the transportation vehicle's brake system in the course of a year.

The technique realized in Mathcad environment [11] contains the following blocks: data analysis, construction of a histogram and graphs of density and a function of the distribution probability (Figure 4) as to brake hoses time-between-failures and assessment of the failurefree operation probability.

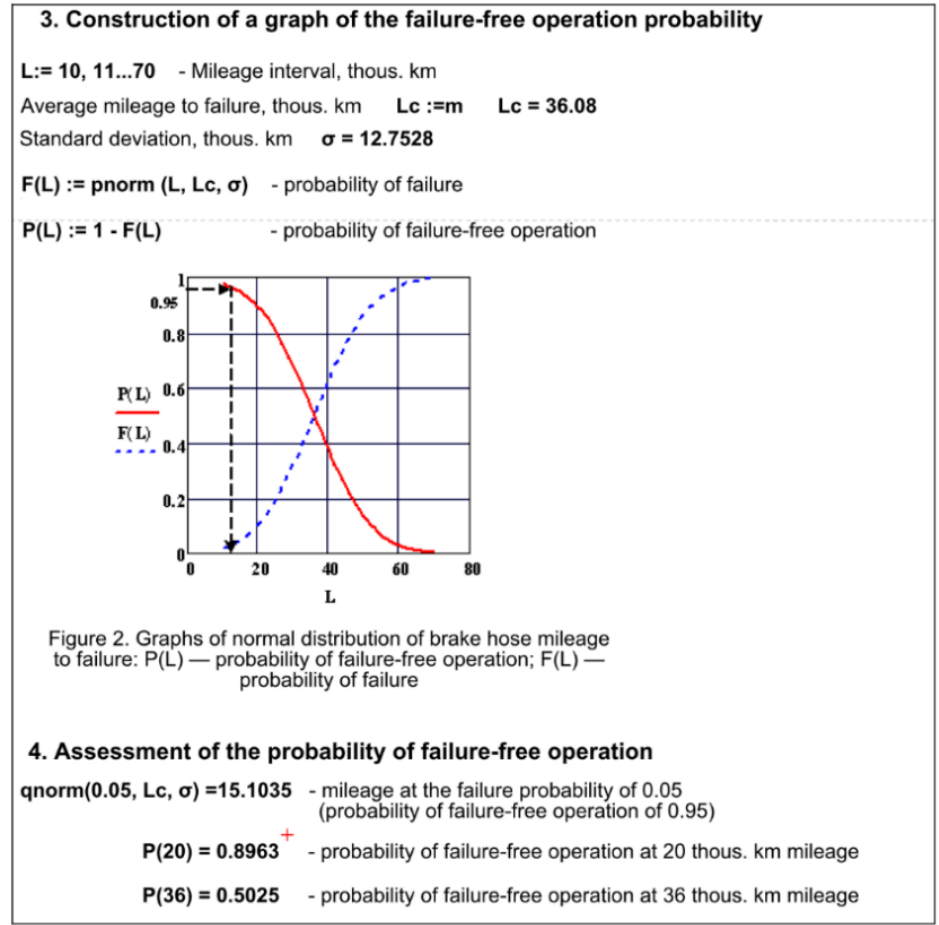

Fig. 4. Block of the assessment of the failure-free operation probability and construction of graphs of density and a function of the mileage distribution probability as to brake hose time-between-failures in Mathcad environment 


\section{Results}

The developed technique allows determining intervals of the replacement of automotive vehicle's elements depending on the required probability of failure-free operation $\mathrm{P}(\mathrm{L})$. For example, for $\mathrm{P}(\mathrm{L})=0.95$, the replacement interval for hoses will be 15 thous. $\mathrm{km}$ (see Figure 4). Upon the replacement of hoses with the mileage interval of 20 thous.km, the probability of $\mathrm{P}(\mathrm{L})$ at the end of the interval will approach 0.89 . In practice, according to our data, the average mileage for the replacement of brake hoses is equal to 36 thous. $\mathrm{km}$, which corresponds to $\mathrm{P}(\mathrm{L})=0.5$.

\section{Discussion}

The need to develop a method for assessing the impact of vehicle reliability on road safety is caused by the need to take urgent measures to reduce the number of accidents due to the poor technical condition of the vehicle. The study of the distribution of the number of accidents due to sudden failures of car systems showed the greatest impact of the brake system.

On the basis of research shows that a significant reduction in the number of accidents due to technical failure is possible only by improving the reliability of the vehicle.

To control the reliability of the vehicle by the methods of technical service, it is necessary to determine the frequency of element replacement by the required level of trouble-free operation, determined using the theory of mass service and structural reliability of machines.

Although the use of the proposed method is demonstrated by the example of only one car manufacturer, the established regularities are also valid for cars of other manufacturers.

The method can be recommended to the service departments of technical service, serving transport companies and private car owners, as well as enterprises for the production of vehicles for the development of action plans for the replacement of machine elements.

In future studies, it is expected to expand the applicability of the method by developing recommendations for the selection of spare parts suppliers according to the criterion of the greatest reliability.

\section{Conclusion}

In recent five years, a significant leap as to the number of road accidents in the Russian Federation due to operation of malfunctioning transportation vehicles was observed.

The study of the distribution of road accidents caused by sudden failures of automotive vehicle's systems showed that the brake system, external lights and alarm system, tires and steering had the highest impact.

The technique of the structural reliability analysis, described in the article, allows assessing the contribution of each element to the total reliability of an automotive vehicle and, thus, the potential risk of road accidents.

In order to increase the reliability of an automotive vehicle, the technique for calculation of the replacement interval for elements of an automotive vehicle, depending on the required probability of failure-free operation, is proposed.

\section{References}

1. Information on road safety. State Motor Vehicle Inspectorate of the Ministry of Internal Affairs of the Russian Federation. URL: http://www.gibdd.ru/stat/files/fdtp/1100/1187/1001.xls (accessed date: 05.06.16).

2. Russian fleet of light automotive vehicles, Analytical Agency "Autostat" [Electronic 
resource] — Available at: http://www.autostat.ru/news/view/20116/ (accessed date: 18.06.16).

3. A.A. Itskovich, N.N. Smirnov, Maintenance and repair of aviation equipment according to its condition. Moscow: Transport (1980)

4. V.S. Malkin, Technical operation of automotive vehicles: theoretical and practical aspects, Teaching guide for students of higher educational institutions. Moscow: Publishing Center "Academia" (2007)

5. E.I. Zaytsev, I.I. Zametalin, V.S. Lukinskiy, Reliability of automotive vehicles. Saint Petersburg: Saint Petersburg State University of Engineering and Economics (1994)

6. R Bujaczek, K Sławiński1, A Grieger Agricultural machines maintenance and repair services in western pomerania. Technical sciences, 16(1), pp. 13-18. (2013)

7. S.V. Repin, K.V. Rulis, A.V. Zazykin, S.A. Krupin, Methodology of ensuring operational capability of transport-technological machines and systems by technical operation means. Saint Petersburg, Saint Petersburg State University of Architecture and Civil Engineering. (2012)

8. S Nosov, V. Kuzmichev, S. Repin, S. Maksimov, Methodology of Ensuring Road Traffic Safety With Respect to Road-Building Materials Compaction Efficiency Factor, Transportation Research Procedia, 20, pp. 450-454 (2017)

9. S.G. Zubriskiy, P.A. Krasavin, A.V. Ruzskiy, Formation of the system for monitoring of the technical condition of transportation vehicles admitted for operation according to road safety conditions, Proceedings of the International Conference "Organization and Traffic Safety Management in large cities", Saint Petersburg (2012)

10. E.A. Shtayts, On possible reasons of road accidents, [Electronic resource]. Available at: http://www.agtu.ru/le_2006_6/sx/art/316794/cp/1/br/.html (2006)

11. S.V. Repin, S.A. Evtyukov, N.N. Krotova, Computer program "Modelling of the structural reliability of a complex technical object (using the example of transporttechnological machines)" (2016)

12. Yu.V. Bazhenov, I.V. Denisov, I.V. Denisov, Study of the failure-free operational brake system of VAZ-21703 automotive vehicles. Modern Problems of Science and Education (2013)

13. A. Kapustin, A. Terentiev, Rational Lifetime of a Vehicle in Terms of Ensuring Security of Its Design, Transportation Research Procedia, 20, pp. 254-260 (2017)

14. I. Arifullin, Conceptual approach to improving road safety by improving reliability of equipment, Paper presented at the Transportation Research Procedia, 20, 21-24 (2017)

15. S. Vorobyov, S. Chernyaev, V. Nazarkin, K. Filippov, Model of Operation of Motor Vehicles Based on Monitoring of their Performance Characteristics, Transportation Research Procedia, 20, pp. 695-701 (2017)

16. A. Afanasyev, D. Panfilov, Estimation of Intersections Traffic Capacity Taking into Account Changed Traffic Intensity, Transportation Research Procedia, 20, pp. 2-7 (2017)

17. M. Suerken, \& T. Peikenkamp, Model-based application of ISO 26262: The hazard analysis and risk assessment, SAE International Journal of Passenger Cars - Electronic and Electrical Systems, 6(1), pp. 114-125 (2013)

18. Z. Yu, \& H. Zhao, Lifecycle safety management system centered on reliabilities for locomotive and car structures. Zhongguo Tiedao Kexue/China Railway Science, 26(6), pp. 1-5 (2005)

19. M. Paslawski, Quality concept in the post-production phase in the car industry. 
Quality Forum London, 18(4), pp. 192-195. (1992)

20. I. Makarova, A. Pashkevich, P. Buyvol, \& E. Mukhametdinov, Risk analysis in the appointment of the trucks' warranty period operation (2018)

21. R. V. Ponnaluri, The odds of wrong-way crashes and resulting fatalities: A comprehensive analysis, Accident Analysis and Prevention, 88, pp. 105-116. (2016)

22. G. Jiang, Y. Zhang, X. Xu, \& D. Ding, Stability and failure analysis of steering tie-rod. Paper presented at the Proceedings of SPIE - the International Society for Optical Engineering, pp. 73-75 (2009)

23. O. Van Schoor, J. L. Van Niekerk, \& B. Grobbelaar, Mechanical failures as a contributing cause to motor vehicle accidents - South Africa. Accident Analysis and Prevention, 33(6), pp. 713-721. (2001) 